\title{
Analysis on Design and Development of China Tourism Products
}

\author{
Jingxu Yao \\ Shandong University Of Arts, China \\ 22073168@qq.com
}

Keywords: Tourism product; Significance; Consumer demand; Product design and development.

\begin{abstract}
Tourism market in China is developed continuously at present. Tourism products still account for low proportion in development of tourism industry. The author systematically analyzes the focuses that should be emphasized in China tourism product design and development from the aspects of tourism product development significance, market positioning of tourism product and consumer demand. They are analyzed for discussing development prospects and future plan of China tourism products.
\end{abstract}

\section{Introduction}

In 2015, China tourism industry is still faced with the 'greatly different' situation. Firstly, domestic tourism market is hot as a whole. Tourism income had become one of main powers to promote the growth of provincial GDP. 'Bulletin about National Travel Agency Statistical Investigation in 2015' issued by China National Tourism Administration shows that 'annual national domestic tour business income was 179.024 billion Yuan; tourism business profit was 9.106 billion Yuan'. Domestic tourism of national tourism agencies was organized for 136.762 million person times and 435.963 million person times. 153.3546 million-person times and 378.7239 million person-times /day were received with year-on-year growth of $4.27 \%, 4.94 \%, 6.07 \%$ and $8.27 \%$ respectively'. In addition, tourism income is still mainly obtained from attraction tickets, hotel accommodation, guide cable car, recreational facilities, etc. Tourism products with high added value, as the core of tourism industry, only accounts for about $20 \%$ in overall tourism industry income. The proportion is account for $50-60 \%$ in European and American countries, which is about $40 \%$ in some developed countries of Asia. Under the background, some people question the necessity of developing and investing tourism products in China, and they think that design and development of tourism products are meaningless and worthless. It is truth?

\section{Analysis on tourism product design and development significance}

1) Tourism product is the material carrier of national culture. It can reflect high-quality culture connotation in China, spread Chinese traditional culture, and carry forward correct social values. Under current globalization situation, culture is the 'personality' label of the country and nation, and it is the precondition for understanding value orientation between countries, seek cooperation and achieve mutual understanding. It is the embodiment of the national 'soft power'. However, culture itself is virtual and spiritual. A transmission medium is insufficient for people in different countries and different nationalities. Traditional media (newspapers, magazines, news media, etc.) spreads at 'spirit level 'educationally'. It is difficult for people in other countries to understand and even they have certain degree of 'resistance'. By contrast, tourism products, as 'touchable' goods, are free from 'political attribute', which can easily enter own countries with consumers for presentation and marketing of our national culture so as to achieve the goal of cultural transmission.

2) Tourism product design can be matched with times and fashion, thereby innovating new products. China directly spans from the handicraft era to the era of industrialization, thereby it is lack of design growth and reflection process of adapting to industrial production. Our own local culture and features are shown especially for definition of design beauty appreciation and how to convert traditional craft into modern design form. Confusion and 'overwhelmed' situation are manifested. 
Most of our products follow 'old style', ancient goods are imitated, or foreign design is copied, and they are lack of thinking and innovation. Design of developing tourism products lies in re-positioning modern beauty appreciation on the basis of own culture. China industry mode is converted from low value-added product processing and assembly into high value-added 'designed in China' and 'made in China'. It has great significance to promote development of entity industry in China, and establish complete industrial chain and even economic transformation.

3) Development of tourism products can promote benign development of tourism industry, protect tourism ecological environment, and prevent excessive development of tourist attractions. Currently, tourism industry income is single at present. A part of attractions blindly increase attraction ticket income, or adopt improper competition means such as false advertising, compulsive shopping, etc. for creating income. The reasons are investigated. Firstly, the cost of 'eating, accommodation and traffic' is relatively open and transparent in tourism industry, and the power of driving industry profit promotion is insufficient. Secondly, most humanity and natural landscapes belong to historical precipitation, which should be mainly protected rather than development. Random expansion is not only conducive to promote industry development, but also may make tourism industry provincial and deflationary, which even destroys original human resource and natural environment, while tourism products can rely on local craft level, cultural tradition, geographical features, material resources, etc. for developing tourism products and increasing industrial added value, thereby achieving multi-level and multi-dimensional promotion of healthy and sustainable development of tourism industry, and reaching green, healthy and sustainable of tourism industry in China eventually.

\section{Market positioning and demand analysis of tourism product}

At present, China tourism market is not lack of all kinds of handicrafts as well as agricultural and sideline products. Scenic spots are provided with a large number of shops and stalls inside and outside. All kinds of small commodities are dazzling and diversified. Therefore, many investors believe that China tourism product markets are saturated, intense competition leads to low tourism product profit. Tourism product market performance is disappointing due to economic factor, purchasing power and other reasons.

The author analyzes existing tourism commodities, and discovers that actual situation is not optimistic. It is mainly manifested in the following five aspects:

1) Commodities are highly similar. Tourism shops are filled with lots of cheap and rough art crafts, such as toys, plastic products, shell jewelry, etc. Shadow play is adopted as an example. The author observes the handicrafts in Xi'an Ancient City, Jinan Yingxiongshan Cultural Market, Hangzhou Xihu Scenic Area and other tourist areas. Appearance, style and process are basically the same. Porcelain, colored glaze, paper cutting, weaving and other technology products are distributed all over the country.

2) Style of commodity is too traditional, which is lack of innovation. For example, Great Wall landscape paintings in Beijing Badaling Great Wall Scenic Spot are not greatly changed in decades. The commodities are common in various network shopping platforms. In fact, sources of the major scenic spots are basically the same. Namely, some commodities similar to local tourism features are purchased from various small commodity shopping malls, which are sold as tourism products. They are not developed by enterprises specifically; thereby product design and innovation are not available.

3) Consumer preferences are not investigated, and the product is lack of fashionable element. At present, China tourism products mostly belong to handicraft works and farmer products. The self-marketing development mode of products is different from modern product development, which focuses on front design and pays attention to consumer demand. Most craft practitioners are basically based on come-down process technology and design style. They work 'behind closed doors' without consideration of market and do not cater to consumer needs, let alone combination with fashion.

4) Craft proportion is too high, which is lack of scientific and technological innovation. The current tourism products are far behind other developed countries because of insufficient modern 
enterprise intervention in the aspects of product development fund investment, development mode and product development personnel level, which can not be changed completely by technology practitioners and local people.

ICSID put forward the new definition of industrial design at the 29th annual conference: design aims at guiding innovation, promoting business success and providing life with higher quality. It tightly combines innovation, technology, business, research and consumers. It is regarded as a chance of establishing better products, systems, services, experiences or commercial network, and new values and competition advantages are provided.' The definition on industrial design is directly targeted to demand objective of consumers in the new century. Higher requirements are proposed for development of modern products - from satisfaction of material function demand to satisfaction of spiritual needs, provision of high-quality service, provision of updated experience and realization of self-value of consumers.

Tourism product design and development also should be positioned. In addition to satisfaction of 'eating, accommodation, traffic and use', the author believes that people's demands in the following three aspects should be further considered in tourism products:

\section{Aesthetic appreciation}

Color design, exterior shape, package design, etc. of tourism products should be based on own characteristics. It does not mean advocating 'static' style. Design aesthetic appreciation should be diversified. Current fashion elements should be combined. Proportion relationship of tradition and modern features and integration of both aspects in artistic appreciation are focused. 'Development is the absolute principle'. Tourism products in line with the aesthetic demand of modern people and provided with own artistic characteristics are goals for design and development.

\section{Emotional factors}

Tourism products should be able to make consumers feel interested, or memorable, or enjoyable, or joyful, or pride, or proud emotion factors, thereby meeting people's demand for spiritual demand. The demand reflects the consumer's sense of belonging and social identity. It is pursuit of people in the aspect of spiritual culture life on the basis of meeting physiological needs.

\section{Cultural connotation}

Tourism product is different from other products. It should carry local geographical features, history tradition and cultural knowledge, which should have certain education and dissemination significance. Confucius temple is adopted as an example. Tourism product design can show cultural inheritance, respect for tradition, historical precipitation, cultural beliefs, etc., which can meet consumers' desire for knowledge, cognition and extension.

\section{Tourism product design and development system analysis}

In summary, the author thinks that China tourism product design and development should aim at actual situation in China. It should be combined with foreign successful experience, which is implemented from the following three aspects:

\section{Precious national culture should not be lost.}

Tourism product design and development cannot be separated from tradition - craftsmanship or art crafts and folk culture should be designed and developed on the basis of the protection. Two aspects should be focused for reaching the purpose. Firstly, universities and colleges are combined to establish special projects for research. Project teams are established in view of excellent traditional culture. Outstanding scientific research resources in college are combined for design innovation, technology innovation, technological innovation, etc. on the basis of research, development and protection of traditional features. For example, 'intangible cultural heritage inheritance person training class' is sponsored by Ministry of Culture and undertaken by Shandong College of Art in 2015 and 2016. New design aesthetic appreciation, design method, design pattern and design management are newly explored on the basis of learning and comprehending traditional arts and crafts-wicker, paper cutting, dough modeling, colored glaze, etc. 
In addition, excellent traditional culture can be built into specific area. Hall, street and city can be formed (such as museums, walking street or ceramic city, etc.). In addition, derivatives can be 'precisely' designed and developed on the basis, thereby maintaining 'original features' of traditional art maximally. For example, special artificial shoes town is formed in Britain Northampton. Artificial shoe-making museum is established in the town. Visitors here not only should comprehend how to produce shoes in complex, strict and delicate procedures. They also can purchase authentic English hand-made shoes. 'Purchase in travel, and learning in purchase' are achieved. Tourism, shopping and learning of traditional culture are combined for mutual promotion, protection, inheritance and development.

\section{Establishment of design brand.}

Own product style should be shaped in tourism products. Tourism product brand should be established on the basis of being positioned in traditional specific culture and specific art, thereby it can adapt to modern design system. In the process, designer should participate in product planning and design in order to grasp fashion trends and increase the design aesthetic appreciation. Tourism product brand can be established for providing own products with distinct features. In addition, excellent products can increase reputation of tourism destination. For example, Dutch Delft Blue is one of three major national treasures in the Netherlands. Many people visit Delft ancient city for tourism due to purchase of ceramic products-visit of production process of specific ceramic products, comprehension of ceramic history, and visit of local blue porcelain museum and amorous feelings of ancient town.

In addition, tourism products also can be cooperated with brand manufacturers. Own products can be developed by local existing enterprise brand or other famous brands.

\section{Tourism product industrialization and characterization}

In 2016 world conference on tourism development, Premier Li Keqiang said that tourism industry refers that 'tourism can drive development of many industries'. It is a major stage for public business and extensive innovation. The government will further improve incentive policy, set up public service platform, and strengthen vocational education and vocational skill training, thereby creating good environment conditions for more people to participate in tourism product development and services.

Tourism products are innovated and created on the basis of local existing material culture for developing more convenient and better mass base. In addition, tourism products also can form own industrialization and characteristic in the following several aspects:

1) Regional consumption characteristics

Local resources and specialties are combined for achieving product features that 'we have the products that other people do not have, we have better quality than others, and we have specific products if other people have the same products'.

2) Culture symbol

Culture is a material element carrier with specific design, custom, memory, art, language, etc. They can be combined with modern design features for rapidly applying the symbols into tourism product design and development, thereby developing own style.

3) Combination with the Internet,

Tourism products can be designed into portable which can be easy to transport or mail or assembly, thereby adapting to modern network marketing model, and realizing synchronous marketing of online store and offline store.

4) Adaptation

More lifelike products with superior practical functions also should be designed aiming at tourism products, such as cosmetics, clothing, shoes, bags, electronic products, etc. As above-mentioned shoes, blue porcelain, etc., tourism products are changed into commodities which rely on tourist attraction but have independent product attributes. 


\section{References}

[1] Jeff Sauro, James R.Lewis, Quantifying the User Experience: Practical Statistics for User Research, China Machine Press,2014

[2] Elizabeth Goodman, Mike Kuniavsky, Observing the User Experience: a Practitioner's Guide to User Research, $2^{\text {nd }}$ ed, Tsinghua University Press,2015

[3] Neil Leonard, Gavin Ambrose, Design Research, China Youth Press,2014

[4] Giles Colborne, Simple and Usable Web, Mobile,and Interaction Design, Posts \& Telecom Press, 2011

[5] Susan Weinschenk, 100 Things Every Designer Needs to Know about People, Posts \& Telecom Press, 2013 